\title{
BMJ Open Subjective experiences of the first response to mental health crises in the community: a qualitative systematic review
}

\author{
Penny Xanthopoulou (D) , ${ }^{1}$ Ciara Thomas, ${ }^{1}$ Jemima Dooley (D) ${ }^{2}$
}

To cite: Xanthopoulou P, Thomas C, Dooley J. Subjective experiences of the first response to mental health crises in the community: a qualitative systematic review. BMJ Open 2022;12:e055393. doi:10.1136/ bmjopen-2021-055393

- Prepublication history and additional supplemental material for this paper are available online. To view these files, please visit the journal online (http://dx.doi.org/10.1136/ bmjopen-2021-055393).

Received 13 July 2021 Accepted 11 January 2022

Check for updates

(C) Author(s) (or their employer(s)) 2022. Re-use permitted under CC BY-NC. No commercial re-use. See rights and permissions. Published by BMJ.

${ }^{1}$ College of Medicine and Health, University of Exeter, Exeter, UK ${ }^{2}$ Mood Disorders Centre, University of Exeter, Exeter, UK

Correspondence to Dr Penny Xanthopoulou; p.d.xanthopoulou@exeter.ac.uk

\section{ABSTRACT}

Objective To review and synthesise qualitative studies that have explored subjective experiences of people with lived experience of mental health-related illness/crisis (MHC), their families and first responders.

Design A systematic review of qualitative evidence was conducted. English-language articles exploring the content of interactions and participants' experiences were included.

Data sources MEDLINE, PsycINFO, EMBASE, CINAHL; Google Scholar, SAGE journals, Science Direct and PubMed.

Data extraction and synthesis Two reviewers read and systematically extracted data from the included papers. Papers were appraised for methodological rigour using the Critical Appraisal Skills Programme Qualitative Checklist. Data were thematically analysed.

Results We identified 3483 unique records, 404 full-texts were assessed against the inclusion criteria and 79 studies were included in the qualitative synthesis. First responders (FRs) identified in studies were police and ambulance staff. Main factors influencing response are persistent stigmatised attitudes among FRs, arbitrary training and the triadic interactions between FRs, people with mental illness and third parties present at the crisis. In addition, FR personal experience of mental illness and focused training can help create a more empathetic response, however lack of resources in mental health services continues to be a barrier where 'frequent attenders' are repeatedly let down by mental health services.

Conclusion Lack of resources in mental healthcare and rise in mental illness suggest that FR response to $\mathrm{MHC}$ is inevitable. Inconsistent training, complexity of procedures and persistent stigmatisation make this a very challenging task. Improving communication with family carers and colleagues could make a difference. Broader issues of legitimacy and procedural barriers should be considered in order to reduce criminalisation and ensure an empathetic response.

\section{BACKGROUND}

Mental health-related crises (MHC) in the community are increasing. This can partly be attributed to increased transitions from institutions to community treatment, ${ }^{1}$ while the COVID-19 pandemic also had an impact,
Strengths and limitations of this study

- As far as we are aware, this is the first systematic review bringing together the experiences of all stakeholders involved in a mental health crisis in the community.

- We undertook rigorous searches for the available literature and assessed the quality of the studies.

- Sixty-six of the included studies were assessed to be of 'high' methodological quality ( $\geq 9$ out of 10 ) and 13 were of 'intermediate' quality ( 7 or 8 out of 10 ).

- The majority of studies were conducted in highincome countries, which could limit the generalisability of the findings.

- This review included studies published in the English language only.

with the National Health Service in the UK, reporting a significant increase in urgent and emergency referrals of people in crisis. ${ }^{2}$ Police and paramedics are often the first responders (FRs) to an MHC. ${ }^{34}$ In the UK, $40 \%$ of police time is spent responding to an MHC. ${ }^{5} \mathrm{WHO}^{6}$ calls for "community actors such as police officers' to be trained in empowering people with mental illness (PMI).

However, there are concerns that FRs cannot provide expert support for PMI and report feeling ill-equipped. ${ }^{78}$ Limited training can result in inappropriate responses, ${ }^{59}$ for instance, tasers are more likely to be used during an MHC than a criminal arrest. ${ }^{5}$ Due to limited resources, the only options available to police have been force and detention. ${ }^{9}$ Section 136 (S136) of the Mental Health Act 1983 gives police authority to detain PMI in a safe place, often a cell, which can worsen the crisis. ${ }^{910}$ Concerns about police capability to make decisions about people's mental health has led to changes in legislation and policy. The Policing and Crime Act 2017 requires that police consult mental health professionals (MHPs) before using S136, use 
a health-based place of safety instead of a police station and reduce the period of detention from 72 to 24 hours. ${ }^{11}$

Ways to improve FR response include specific training tools, ${ }^{12}$ which mainly involving de-escalation techniques for police, as well as models of triage ${ }^{7}$ that aim to improve police officers' ability to provide effective response. ${ }^{13}$ Triage includes Crisis Intervention Teams (CIT), where a police member is trained in MHC intervention, and co-response/interagency collaborations between FR and MHPs. ${ }^{7}$ The aim is to improve response and to reduce the likelihood of detention. ${ }^{7}$ A recent review ${ }^{13}$ of interagency collaboration models found that there is a wide range, with different kinds of agencies and services involved at various levels. Co-responder interventions are not routine practice and the majority not evaluated,${ }^{13}$ and high costs, logistics ${ }^{13} 14$ and limited access to local mental health services ${ }^{15}$ make such models difficult to implement.

Currently, evidence on FR interactions and communication practices in incidents involving PMI is not well documented. ${ }^{11}$ Factors that impact on the interactions between FRs and PMI need to be understood better and integrated into training to improve response. ${ }^{16}$ Significant research focuses on service development, however there is a need for research on lived experiences and interactions as they unfold in real time, exploring the perspectives of all stakeholders, including companions (family/carers/friends). ${ }^{17} 18$ With rises in mental distress and illness worldwide, identifying experiences of the responses to MHC from all people involved is critical. Hence, the aim of this study was to review available qualitative evidence on the subjective experiences of people with lived experience, their companions and FRs, of the FR response to mental health crises in the community.

\section{METHODS}

The PICo for qualitative studies (figure 1) was used to identify the Population of interest, the phenomena of Interest and the Context. ${ }^{19}$

\section{Search strategy}

A systematic search was conducted using the MEDLINE in Process (Ovid), PsycINFO (Ovid), EMBASE (Ovid) and CINAHL databases. Relevant research was also identified using Google Scholar, SAGE journals, Science Direct, PubMed, Hand searching systematic reviews' reference lists, reference checking and citation chasing of included studies. A search strategy was developed using controlled

\begin{tabular}{|lll|}
\multicolumn{1}{c}{ Population } & \multicolumn{1}{c|}{ Interest } & \multicolumn{1}{c|}{ Context } \\
- People with lived experience of a MHC & The lived & The interaction \\
- FRs: police, paramedics, firefighters, & experiences & in community \\
emergency medical technicians & of the & settings. \\
- Companions present in MHC (e.g. & response. & \\
carers, family, friends) & & \\
\hline
\end{tabular}

Figure 1 Population of interest, the phenomena of Interest and the Context. FR: first responder; MHC: mental healthrelated crisis. vocabulary unique to each database and free-term texts including three search groups: MHC; non-mental health emergency responders and qualitative design (online supplemental appendix 1).

\section{Selection criteria}

Retrieved articles from the inception for each database to November 2020 were included, if they directly related to all three search groups. Articles published in English were included because there was no multilingual researcher in the team, and finite resources. Studies reporting perspectives/experiences, involving adults ( $\geq 18$ years) and using a qualitative approach, including mixed methods with a clear qualitative aspect. We only included qualitative articles to allow for understanding of the experiences of all stakeholders involved in these interactions. Studies with exclusively quantitative data, non-adult participants that reported solely on MHPs and the MHC did not occur in the community were excluded.

\section{Screening, data extraction and synthesis}

Two reviewers conducted an initial screening of all titles and abstracts against the inclusion criteria to identify relevant papers. Duplicates were removed. Retrieved records were first screened on title and abstract. Reviewers screened the relevant full papers, and studies were independently assessed for eligibility. Disparities were resolved in weekly meetings before proceeding to the next stage. The Critical Appraisal Skills Programme (CASP) Qualitative Checklist ${ }^{20}$ was used to appraise the methodological quality of the articles. The extraction and analysis of the qualitative studies was iterative ${ }^{21}$ and was reviewed in weekly analytic meetings. Findings of each study, including participant quotations and author interpretations, were examined, extracted and assigned to descriptive codes in NVivo 12. Inductive thematic synthesis was used where findings of primary studies were coded line by line and similar characteristics were then grouped together and given a label to describe the content. These descriptive labels (codes) were then grouped into 'subthemes', which were then developed into descriptive themes. This process was conducted by two authors (PX, CT) and in two further analytic meetings (JD).

\section{Patient and public involvement}

Exploratory work in 2019 was conducted with:

1. carers and people with lived experience (South West England);

2. five ambulance service staff;

3. Devon and Cornwall Police lead and for enhanced communication.

FR response was described by carer and PMI as 'hit and miss', 'dismissive' and positive "they [police] always looked after me". FRs described the challenges they face and lack of, or difficulties in following prescriptive training. This led to development of aims of this review and the focus on real-life experiences. 
PRISMA Flow Diagram

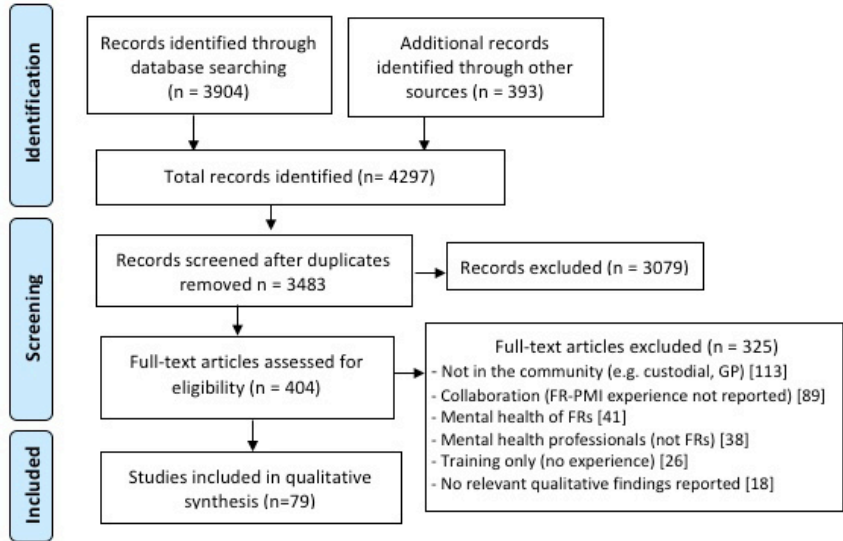

Figure 2 Preferred Reporting Items for Systematic Reviews and Meta-Analyses flow diagram of included and excluded studies. FR, first responder; GP, general practitioner; PMI, people with mental illness.

\section{RESULTS}

The electronic and hand searches identified 4297 studies (figure 2). Seventy-nine studies, including three unpublished, were included in the review (table 1). These studies used semi-structured qualitative interviews $(n=43)$, focus groups $(n=4)$ and mixed methods $(n=32)$. Studies explored the perspectives of the police $(n=35)$, paramedics $(n=13)$, PMI $(n=15)$, carers or family members $(n=8)$ and multiple stakeholders $(n=8)$. No other FR perspectives, for example, firefighters, were found. The studies were conducted in the UK $(n=22)$, the USA $(n=22)$, Australia $(n=15)$, Canada $(n=10)$, The Netherlands $(n=2)$, New Zealand, France, Sweden, Ireland, Ghana, Slovenia, Portugal and Guyana (each $n=1)$. All scored 7 or higher on the CASP Checklist (table 1), indicating medium to high quality; no exclusions were made on this basis. Reasons for lower scores were: (a) not reporting on the relationship between researchers and participants, (b) limited reporting on ethical issues and (c) not detailed reporting on the analysis.

Table 2 presents the themes and subthemes from the thematic synthesis of the included studies, which all contained first-order themes.

\section{Acknowledging versus criminalising mental illness and procedural concerns \\ Criminalisation and use of force versus recognition of behaviour relating to mental ill health}

Companions and PMI described distress, fear, confusion, humiliation and trauma caused by a large police presence, disproportionate use of S136, involuntary transport and physical restraint ${ }^{1822-32}$ : "You're confined in this tiny, small box and you go, 'what's happening to you?' They don't speak to you, and the only time they do, they're barking orders at you" (PMI). ${ }^{33}$ FRs were sometimes perceived as threatening: "I said I am going to call 911, and he said: 'no don't, if you call 911 they are going to kill me'" (companion). ${ }^{22}$ In one study, paramedics describe disliking physical restraint and excessive force, believing their presence alone can be calming. ${ }^{34}$ In contrast, police described their 'right to use force', ${ }^{26}$ arguing that force and restraint were "most helpful because they immediately make the situation unpleasant for the individual ${ }^{935}$ Police felt victimised when criticised for using force. ${ }^{34-37}$

PMI and their family/carers described instances where crises were not resolved. Time delays, use of force and FRs'

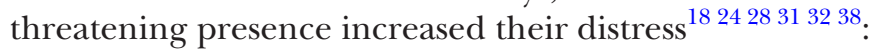
"[Six police officers] were standing there with their capsicum spray...I was just sitting there bawling my eyes out...It made me feel one hundred times worse" (PMI). ${ }^{32}$ Impacts of these responses on PMI include fear, mistrust, trauma and posttraumatic stress disorder. ${ }^{39}$ PMI felt degraded and traumatised: "I was handcuffed, led out into the street, head pushed down and into a police car. It is humiliating, the police were scaring me, neighbours witnessed the disturbance, and localyouths came out to shout and jeer from the side lines". ${ }^{40}$ Companions reported being interrogated by police, which exacerbated the situation, ${ }^{41}$ and that mental illness was ignored ${ }^{42}$ : "So the victims have become the criminals" (carer). ${ }^{22}$

In contrast, PMI and companions praised FRs when they used a gentle approach, avoided excessive force by engaging meaningfully with them, using de-escalation and communication techniques. ${ }^{1828-32} 35374043-48$ They valued FRs being professional, non-judgmental and compassionate, providing reassurance, expressing a wish to help, asking for permission to examine or touch the PMI, and including them in decision making. ${ }^{18} 2431324548-51$ FRs assumed a non-threatening presence by maintaining eye contact, not standing with arms crossed, altering their tone and taking a low-profile approach to protect PMI privacy, and by not using police uniform or vehicles. ${ }^{26} 3034374052$ FRs suggested using direct questions to avoid confusion and stress: "the less you say, and the more you listen, the better the call will go... do you actually need to obtain that information, or is it just agitating" (paramedic), ${ }^{40}$ and using humour to distract and calm the PMI. 303234354045 53-55

\section{Accountability, cautiousness and confusion over procedure}

FRs expressed concerns and confusion about the law, in detaining PMI, which made decision making difficult ${ }^{26} 3031363747545657$ : "They don't fully understand how to use the Mental Health Act...I think there's a lot of officers out there who have a lack of knowledge of what we can and can't do" (police officer). ${ }^{36}$ Some police officers suggested detainments are voluntarily because, ${ }^{36} 37$ and when PMI have crises at home it is illegal to enact S136. They described pressure from colleagues to detain PMI when they did not meet the requirements of S136, ${ }^{36}$ and said that they often prioritised the safety of the PMI over the law in order to take them to hospital 30313654 : "I'd rather get into trouble ethically for taking somebody against their will than somebody die, and I left them there to die" (paramedic) ${ }^{30}$ During MHC, FRs worried about being blamed, scrutiny, losing their job and pension, and felt they had to cover themselves 17303135475657 : "It's just not worth losing my job over people who don't care about themselves" (paramedic). ${ }^{56}$ Police 


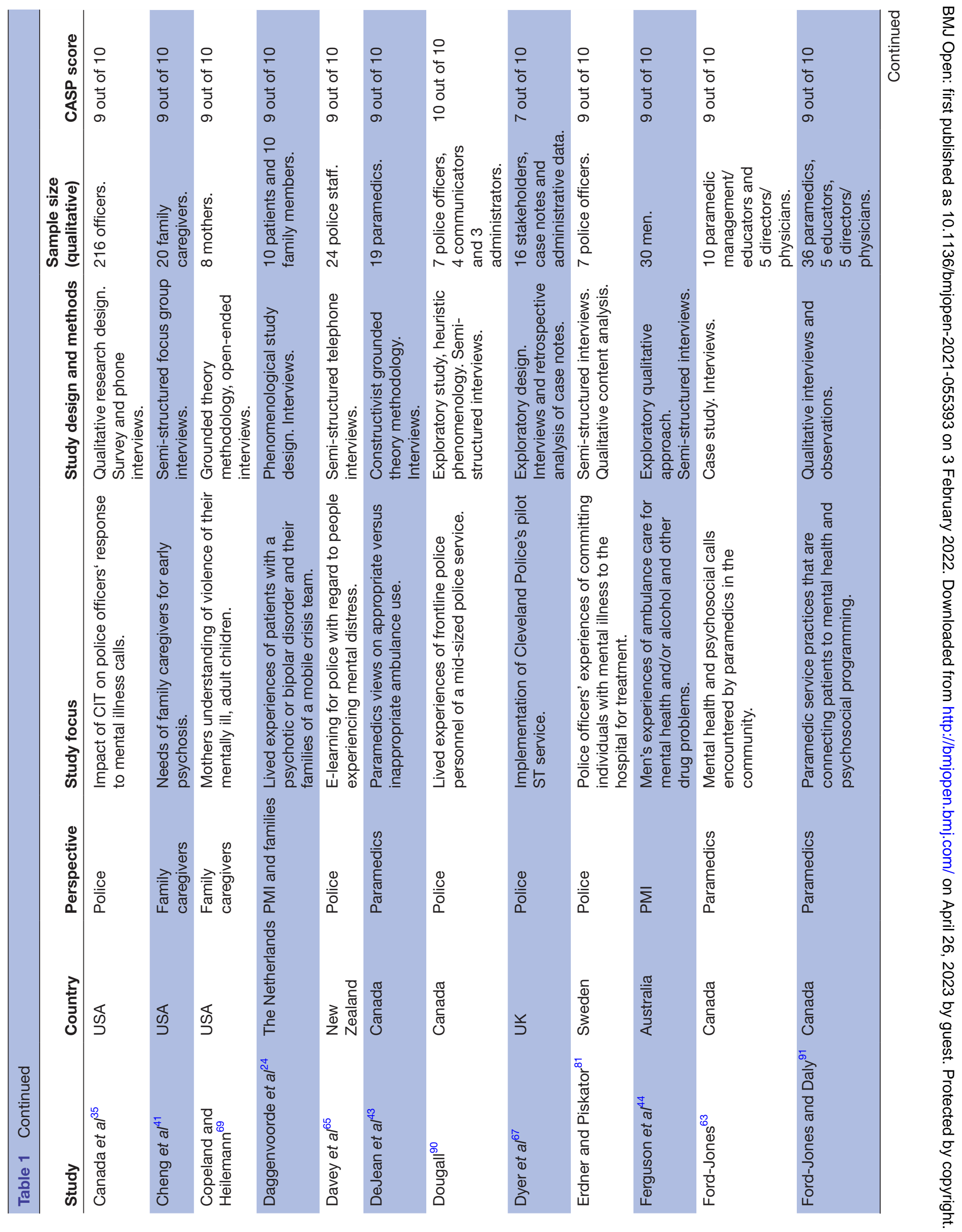




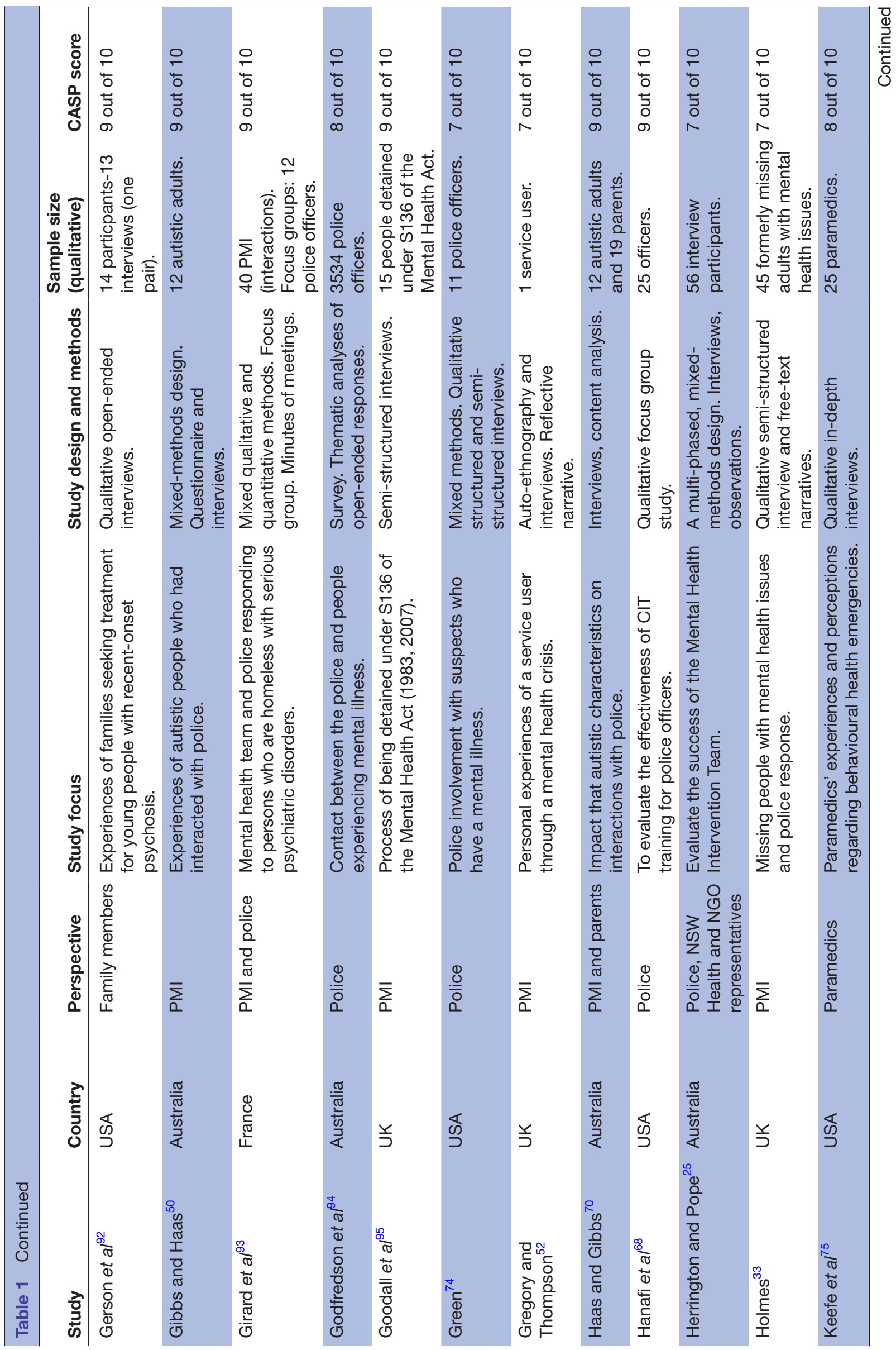

O

ज

흠

$\frac{\bar{c}}{\mathrm{c}}$

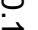

응.

N

í

을 


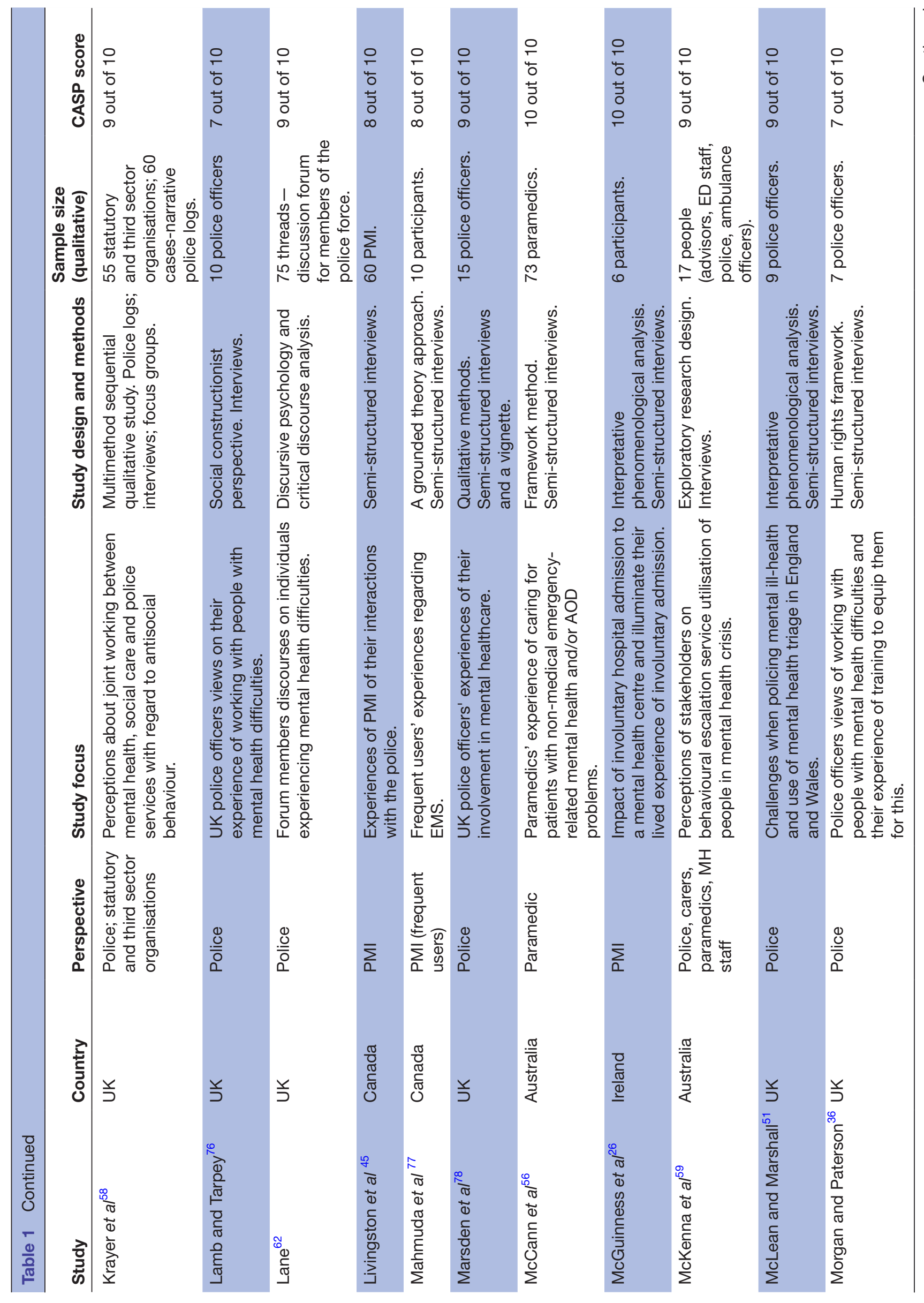




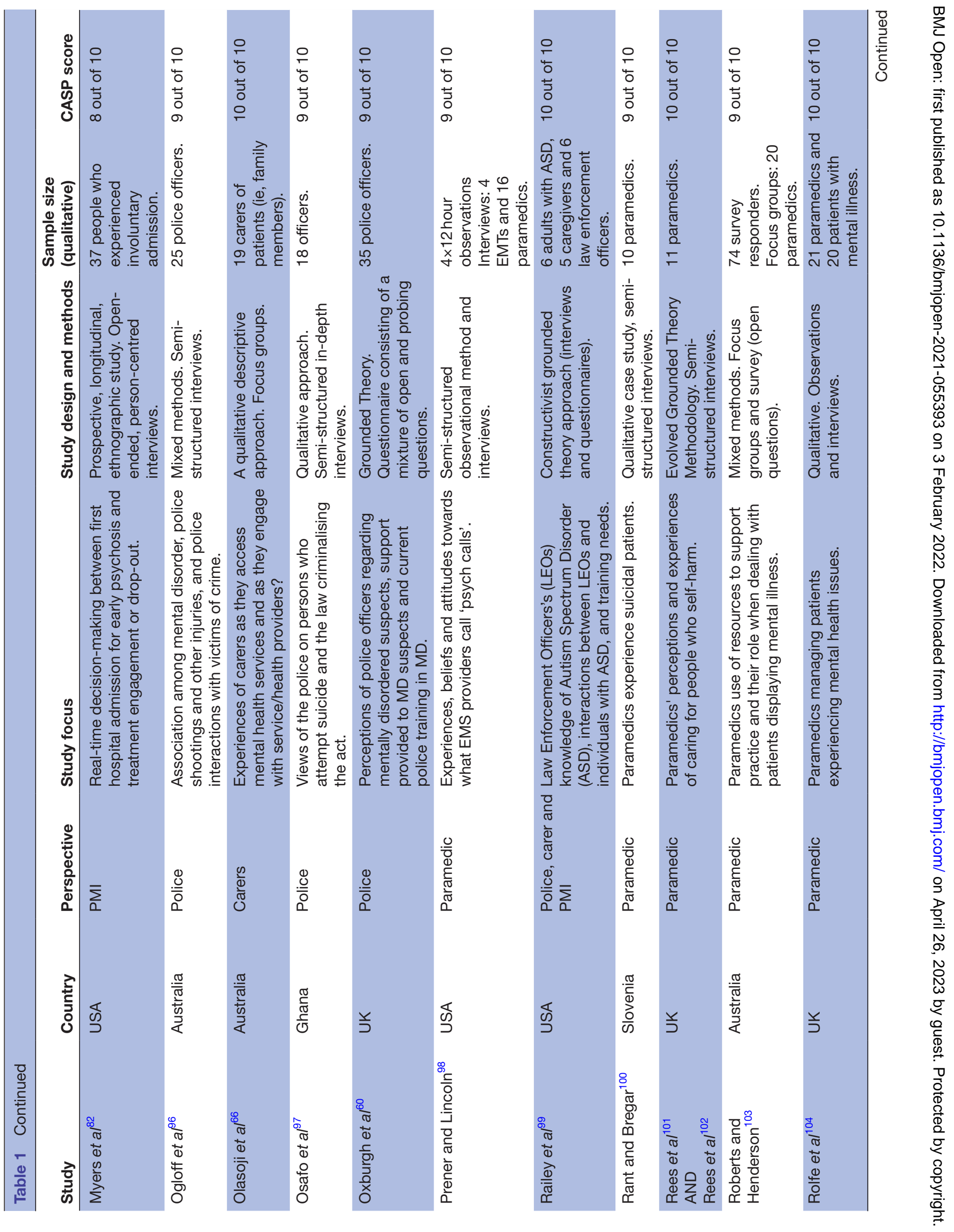




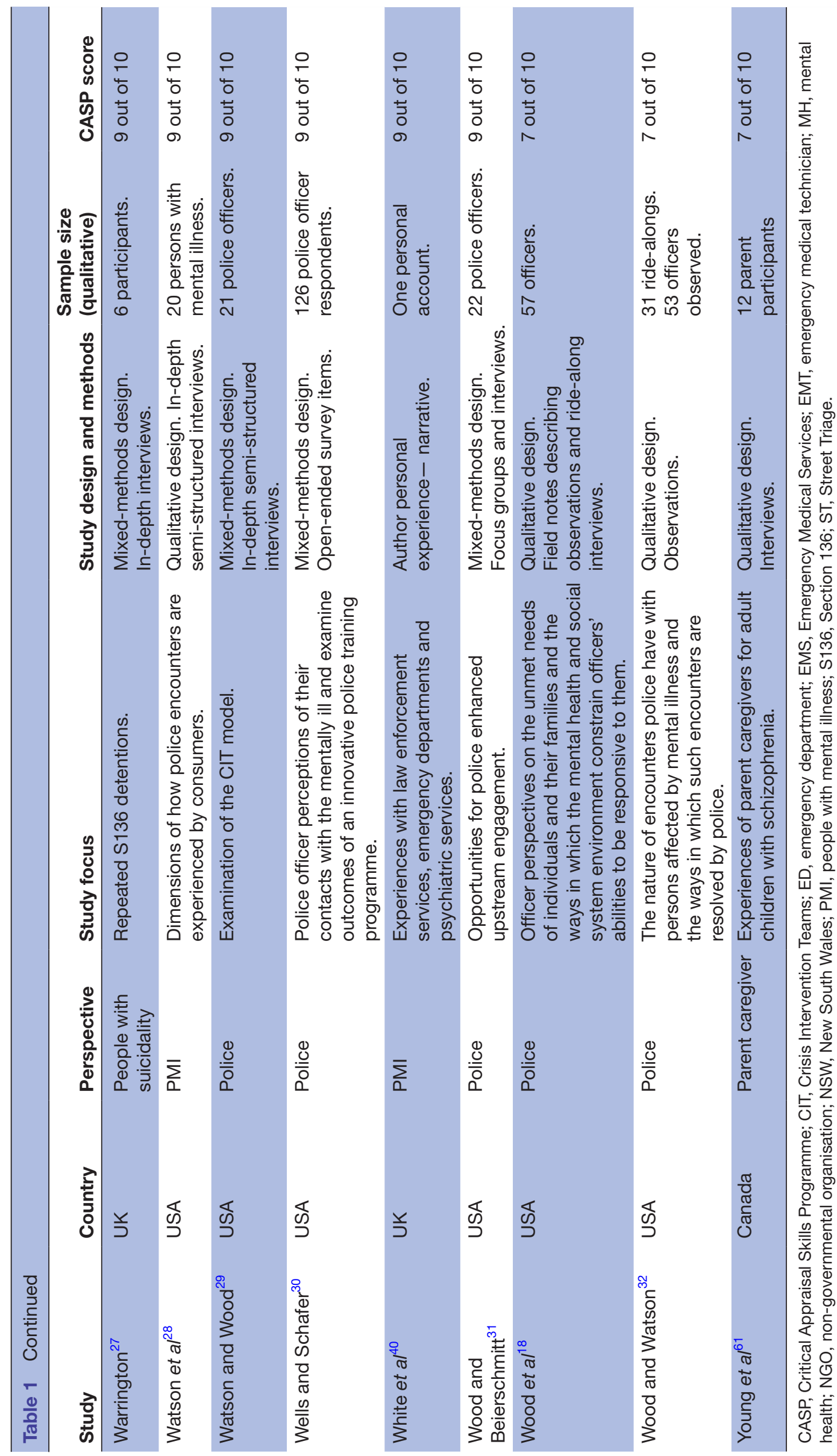


Table 2 Themes and subthemes

\begin{tabular}{|c|c|c|}
\hline Theme & Subthemes & Studies exploring each subtheme \\
\hline \multirow[t]{2}{*}{$\begin{array}{l}\text { Acknowledging versus } \\
\text { criminalising mental illness }\end{array}$} & $\begin{array}{l}\text { Criminalisation and use of force versus } \\
\text { recognition of behaviour relating to mental } \\
\text { ill health. }\end{array}$ & $\begin{array}{l}22-24,26,32,34-35,41,45,51,53-54,59,63 \\
66,81-83,87,90-97 . \\
\text { (Canada, USA, UK, Australia, Ireland, Portugal) }\end{array}$ \\
\hline & $\begin{array}{l}\text { Accountability, cautiousness and confusion } \\
\text { over procedure. }\end{array}$ & $\begin{array}{l}\text { 17, 62-63, 65-67, 79, 82-83, 85, 93, } 95 . \\
\text { (Australia, Ireland, Portugal, UK, USA) }\end{array}$ \\
\hline \multirow[t]{2}{*}{ Legitimacy and stigma } & $\begin{array}{l}\text { Non-legitimacy of mental illness and impact } \\
\text { on seeking help. }\end{array}$ & $\begin{array}{l}23,29,45,50,53,59,62,64-66,79,81-87,89 \\
90-91,93-95,97 . \text { (Australia, Canada, Portugal, } \\
\text { UK, USA) }\end{array}$ \\
\hline & Stigma and use of stereotypes. & $\begin{array}{l}\text { 17, 23, 29, 34-35, 40, 51, 58-60, 62-63, 66, } \\
\text { 71, 81-87, 92, 98. (Australia, Canada, The } \\
\text { Netherlands, Portugal, Sweden, UK, USA) }\end{array}$ \\
\hline \multirow[t]{2}{*}{$\begin{array}{l}\text { First responder capability } \\
\text { and skills dealing with mental } \\
\text { health crises }\end{array}$} & Training: impact and requirements. & $\begin{array}{l}32,35,41-42,50,52,56,59,62,64-66,70,79 \\
81-87,89,93-96,98 . \text { (Australia, Canada, Ghana, } \\
\text { Guyana, The Netherlands, Portugal, UK, USA) }\end{array}$ \\
\hline & The value of personal experience. & $\begin{array}{l}50,57,62,66,74,79,83,87,93-94,97 \text { (Australia, } \\
\text { Portugal, Slovenia, UK, USA) }\end{array}$ \\
\hline \multirow{2}{*}{$\begin{array}{l}\text { Impact of response on } \\
\text { companions: involvement } \\
\text { hindering versus facilitating } \\
\text { response }\end{array}$} & $\begin{array}{l}\text { Companions ignored, not informed and } \\
\text { impact on them not recognised. }\end{array}$ & $\begin{array}{l}\text { 23-25, 29, 33-35, 91, 93-98 (Australia, The } \\
\text { Netherlands, USA, UK) }\end{array}$ \\
\hline & $\begin{array}{l}\text { Companion involvement: hindering } \\
\text { response versus leading to better } \\
\text { outcomes. }\end{array}$ & $\begin{array}{l}\text { 35, 45, 83-86, 94-95, 97, 98. (Australia Canada, } \\
\text { USA, UK, Portugal, The Netherlands) }\end{array}$ \\
\hline
\end{tabular}

officers shared their anxiety and sense of responsibility for suicide victims and their families. ${ }^{57}$

\section{Impact of perceived legitimacy and public stigma}

Non-legitimacy of mental illness and impact on seeking help

Many studies reported how often mental health crises were not considered a 'real' emergency. FRs reported that responding to MHC was 'babysitting', frustrating and a waste of time and resources, reporting that it damaged their public image. ${ }^{30} 3134404548535859$ FRs perceived PMI as selfish and taking support from other, more deserving incidents, confronting the PMI 28344046475156 : "Next time you have the urge to pretend to kill yourself do not call us, call someone who can help. Because while we are pampering to your selfish needs there are others who really do need our help who are not getting $i t$ " (paramedic). ${ }^{34}$ These encounters often resulted in the PMI feeling ashamed: 'Emotions varied and included shame and embarrassment at having wasted police time. ${ }^{28}$

Legitimacy towards PMI was particularly challenged by FRs when it involved frequent users of mental health services: "we've had patients who attempted to commit suicide every week, just to let out their frustrations... to get our attention. I feel no empathy for such people" (paramedic). ${ }^{34}$ However, FRs also described PMI being frequent users of emergency services due to ineffective health systems overusing services as a 'band aid approach'. 18273036374851525456 PMI were often released from hospital the same day police transported them, leading to future crises requiring police response: "vicious cycle...you are exposed to that cycle so many times of taking people in, nothing happens, they get released, taking people in, nothing happens, they get released" (police officer). ${ }^{36}$ Additionally, FRs described forming relationships with frequent users, building trust and knowing what to say to reassure PMI. ${ }^{30} 3255$

Negative interactions with FRs caused PMI and companions to be reluctant in seeking help. Being treated with force and physical restraint, or at worst the PMI being killed during an encounter with FRs, led to many regretting having called for emergency help ${ }^{2730-32404648495457}$ : "I am afraid to call them. They have exasperated traumatic events. They have belittled me for my appearance, so I stopped wearing my helmet" (PMI). ${ }^{54}$ This was also demonstrated in the low standards PMI had for interactions with FRs: "I didn't get beat up, I didn't get thrown down stairs, I didn't get punched or kicked, I didn't get tazed, that kind of stuff, so, it was good" (PMI). ${ }^{24}$ Family/Carers described feeling guilty and blamed themselves for calling the police $22{ }^{3750}$ : "It was that one phone call, that one phone call destroyed everything. If I could just take it back" (parent). ${ }^{22}$

Person with mental illness dehumanised, use of stereotypes and stigma

Studies demonstrated that the stigmatisation of PMI involved fear and beliefs that PMI are unpredictable, violent, dangerous and lack insight about their

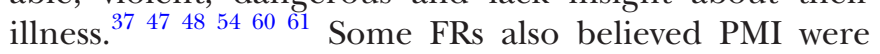
incapable of cooperation and had an increased pain 
threshold'. 262945464962 PMI reported being treated in a dehumanised way: "They just handcuffed me like a dog, they fired me in the back of the van like a dog and they just left me in there" (PMI). ${ }^{26}$ PMI were treated as if they were in control of their mental health, and accused of being manipulative and disingenuous. ${ }^{40}$ After police learnt of PMI's mental illness, PMI describe a negative change in their attitude ${ }^{24}$ including not listening or take PMI seriously, using stigmatising language, laughing at PMI and being insensitive, disrespectful and judgemental 18243454 : "You can tell right away that they all have the same look and that stuff" (police officer). ${ }^{55}$ However, many studies found that FRs condemned mental illness-associated stigma and believed PMI deserved to be treated with the same urgency and professionalism as physical injuries ${ }^{1830} 313436374047535456$ : "Just because we're cops doesn't mean we're better than them... would you be angry with him if he had cancer?" (police officer)..$^{53}$

\section{First responder capability and skills dealing with mental health crises}

Role requirements and training: recognising symptoms of mental illness

FRs often failed to resolve MHC, as they believed MHC response is not part of their role, they have too much responsibility, and they felt let down by inadequate mental health services. $30313436374046-4852535758$ Due to limited hours and resources of mental health services, FRs were often the only service available to deal with MHC. Police felt they have few options when hospitalisation was impossible: doing nothing or arresting PMI for 'breach of the peace'. ${ }^{32} 3435405459$ A confusion regarding their roles and responsibilities was documented; many FRs believed they had a duty of care 34363747515258 while others stated they should not respond to MHC, which was shared by some PMI and family/carers. ${ }^{36} 405658$

FRs felt unequipped to respond to MHC due to their lack of knowledge, resources and time constraints ${ }^{25-27} 31343740444552-54565763$ 64: "training makes it look straight forward and it's dead simple... and then you go out and it's just a different game" (police officer). ${ }^{45}$ Police described their past reluctance to ask PMI direct questions, thinking they would distress them, and instead asked vague questions that overwhelmed and confused PMI. ${ }^{40}$ Carers reported that police were unprofessional and, in some cases, refused to take the PMI to the hospital. ${ }^{1824303237485054}$ One officer argued that families do not understand the requirements of detainment, but others described incentives and initiatives to reduce use of S136. ${ }^{35}$ FRs described their mental health training as minimal, unspecific, unhelpful and not prioritised, resulting in poor knowledge and inability to manage MHC. ${ }^{31} 343640454752$ 54-57 Paramedics felt isolated during MHC, lacked guidelines to support their decisions and used a trial-and-error approach. ${ }^{30} 3140{ }^{54}$ A lack of training promotes fear, stigma and stereotypes, putting PMI at risk of excessive force and criminalisation. ${ }^{24} 32454755$
PMI believed FRs need training in compassion, patience, communication skills, de-escalation techniques, building rapport, asking questions and confidentiality. ${ }^{24} 28344552$ After CIT training, FRs reported better understanding and identification of MHCs, and being equipped to ask direct questions and spend more time with PMI. 2526343540464753 Training reduced the unpredictability of MHC and FRs felt safer, more confident and patient. ${ }^{3543586566}$ Training normalised mental illness and increased FR empathy by challenging stigma and stereotypes, resulting fewer injuries and arrests and more support for PMI 25263435464753556768 : "You know, after you come out of CIT training, you understand that it's an illness that's treatable and that, you know, just normal people can suffer from a mental illness" (police officer). ${ }^{68}$ However, a number of FRs reported that training would be of no use without adequate mental health services. ${ }^{3446}$

\section{Interagency collaboration for crisis response}

Paramedics valued police involvement because of their familiarity with the public and ability to encourage patients to go to hospital. ${ }^{4051}$ Police valued how collaboration can prevent arrests and challenge agency stereotypes. $^{30} 40454651$ PMI and carers found initiatives such as the Street Triage response friendly, effective and safe, ${ }^{18252832}$ and police felt that it improved relations between paramedics and police, leading to better and faster response. ${ }^{25} 26283545$ However, FRs also described onsite tensions, power struggles and arguments about who should take the PMI to hospital, and which behaviours posed a 'serious threat'. 253136404755 In addition, police were frustrated at paramedics' low-level priority for PMI and long waiting times that caused distress. ${ }^{38} 69$ Sometimes police decided not to call for an ambulance. ${ }^{36}$ One PMI reported a lack of collaboration between agencies, and that the multi-agency response was overwhelming. ${ }^{32}$ Police also describe how agencies rejecting PMI under the influence exacerbated mental distress and left them no choice but to arrest PMI for their own safety. ${ }^{1828304653}$ Police did not know who to call or what resources were available. ${ }^{52}$ PMI believed that even a gentle response from police, without MHPs present, was irrelevant because police are not qualified. ${ }^{243145}$

\section{The value of personal experience}

FRs believe that personal experience of mental illness is more valuable than formal training. They described how personal experience and 'on the job training' aided their responses significantly more than formal training 3032343637405256 57: "I don't think there's any textbook that can teach you" (police officer) ${ }^{57}$ FRs described using common sense to guide their approach: "after 22 years $I$ get a pretty good idea of whether someone's off their... basically mentally incapacitated or not. I don't know I would probably go on a gut feeling more than anything else" (police officer). ${ }^{30}$ Paramedics believed responding to MHC is too complex and that they are always learning on the job. ${ }^{34} 36374057$ 
Impact of response on companions: involvement hindering versus facilitating response

Companions ignored, not informed and impact on them not recognised

Companions reported not being informed as to why there was an arrest and what will happen next. ${ }^{24} 28314049$ They described the crisis response as intrusive, terrifying and traumatic. ${ }^{182430-324061}$ They reported receiving no support after the crisis, which worsened their suffering: "No one would ring me up and talk to me. Here I was, a mother in crisis because her son [was in] crisis" (mother). ${ }^{49}$ This lack of support for companions was also reported by FRs. ${ }^{40}$ Failure to communicate with $\mathrm{PMI} /$ companions worsen the crises: "If they had sat down with me instead and said 'okay, do you want to tell us what's been going on'... it would have been easier and they wouldn't have needed the handcuffs because I wouldn't have ran" (companion). ${ }^{28}$

\section{Companion involvement: hindering response or leading to better} outcomes

PMI preferred an informal crisis response involving friends and family ${ }^{32}$; however, the interaction between FRs-PMI-companions is complex: 'The family can be very instrumental in helping... sometimes the family is actually more difficult to manage than the patient' (paramedic) ${ }^{40}$ During a crisis, family members felt responsible for the PMI and calling the police was a last resort. ${ }^{24}$ FRs reported that family presence can complicate their response, as sometime there may be conflict between the PMI and family members. ${ }^{32} 3740$ When the presence of family prevented PMI cooperation, sometimes due to shame, paramedics separated the family: "They just don't want friends/family knowing what they're going through" (paramedic). ${ }^{31}$

However, in many instances, PMI and police described family and friends' involvement as calming and encouraging ${ }^{40}$ 47: "I was sort of like cajoled by my brother and my mate ... they said, oh you know they wanted to take me to (the psychiatric hospital), and I said right-oh, no worries" (PMI). ${ }^{31}$ Police obtained information from parents about PMI, for example, whether they are aggressive or cooperative, to enable an appropriate police response ${ }^{3750}$ : "When it is the first time for us with that person to be transported, the first thing we do is to contact a relative to know about what type of person he is" (police officer). ${ }^{31}$

\section{DISCUSSION}

This review of the qualitative studies aimed to identify and synthesise findings from published studies on the subjective experiences of stakeholders involved in incidents/crises which involve PMI. Findings reflect the variety of experiences and complexity of responding to $\mathrm{MHC}$ in the community. Recognising mental illness as a legitimate condition and responding with empathy rather than force and stigmatising attitudes was valued by PMI and their companions. To achieve this, all stakeholders called for further training. FRs highlighted issues regarding the law, procedures and accountability which may constrain the response. Despite the inevitability of their involvement in these incidents, many FRs do accept they should have a role in managing mental illness in the community. Personal experience of mental illness can make a difference in the response as well as collaboration between FR services and mental health services. Finally, the role of third parties present in the interaction, such as family, friends and carers, was recognised by all stakeholders, which adds another level of complexity to these interactions.

Evident in the majority of studies was that while many FRs engaged meaningfully and empathetically to resolve crises, a significant number of interactions involved excessive force, physical restraint and stereotyping, which often humiliated and traumatised PMI and their companions. ${ }^{18}$ 22-24 27-32 3435373840424553546970 Previous reviews $^{71-73}$ reported FRs' reasons for force, such as their duty of care, bystanders and themselves, and that PMI are likely to be resistant and this would require proportionate force. FRs suggested that using force is required to gain control and central to their profession, and dealing with MHC was not, at least officially, a central part of their role. $^{25} 2633363745515256585962687074-78$ However, the role of FRs in managing mental ill health in the community is vital and likely to increase due the COVID-19 pandemic, ${ }^{79}$ the subsequent economic crisis, as well as climate change, which disproportionally affects vulnerable people and can be the cause for mental illness. ${ }^{80}$ Similarly, although interagency collaboration models where MHPs are located in police stations or police cars, can improve response, ${ }^{18}$ most of these models are not evaluated, and high costs, logistics and limited access to local mental health services make such interventions difficult to implement. ${ }^{13}$ Lack of understanding and inadequate policies and procedures create a somewhat understandable confusion for FRs as well as fear that leads to the criminalisation of PMI.

Issues of stigmatisation and disregarding mental illness as a legitimate health condition were also revealed in the studies. $172224262934363745-4953545660-6269707781$ This demonstrates the difficulty of eliminating stigma, unconscious bias and the unintended consequences of attitudes. New studies $^{82}$ continue to find stigmatising views among officers. We found that although all FRs wanted to challenge stigma, ${ }^{18} 30313436374047535456$ there was a variation in attitudes and practice. A review ${ }^{83}$ also found diverse attitudes towards PMI among FRs, for example, more experienced paramedics had more anger towards PMI and saw them as irritating and a waste of time, whereas others found that more experienced paramedics had more empathy. This suggests, perhaps that in order to dismantle prejudices, personal experiences of FRs, PMIs and their companions need to be incorporated in education and training, as personal and not necessarily more experience can lead to a more empathetic response.

Views from all stakeholders in this review revealed a confusion over whether FRs were the appropriate service for MHC response. Many believed they were not qualified, that mental health services were responsible 
and that training is futile with an inadequate health system. $^{34} 4669$ Previous reviews ${ }^{73} 84$ also reported that improving these interactions is irrelevant when there are no support services available, which often results in 'frequent attenders', where inadequate response in emergency and in-patient settings leads to a cycle of repeated crises. Stakeholders had conflicting views on interagency collaboration but was overall valued by FRs. ${ }^{30} 40454651$ Although guidance suggests that police 'should expect support from' health and social care services within locally agreed timescales', ${ }^{6}$ FRs in the majority of studies emphasised lack in resources. Both paramedics and police viewed dealing with MHC as a superfluous part of their role. Different types of training for police and paramedics could help integrate MHC response into their 'official roles' and alleviate tensions between the PMI needs versus the organisation's needs.

All stakeholders called for training to improve FRs' understanding and knowledge of MHC and to breakdown stigma and stereotypes. ${ }^{25} 263435464753556768$ FR criticism of their mental health training indicates an interest and need in improving MHC response. In line with other research, ${ }^{85}$ we found that personal experience is valued by police officers. 'On-the-job training' was perceived by some as more important than formal training. 303234363740525657 Evidence that colleagues sharing their personal experience can help understanding and response, as well as CIT training, ${ }^{686}$ shows that better strategies that can help FRs are available. This highlights the importance of finding ways for FRs to share their practical knowledge and skills during training or team meetings.

Mental health crises will often take place in a person's home with others, often family, present. In line with research of parents of children with psychosis, ${ }^{87}$ companions described the, often traumatic, impact of the FR response and a lack of inclusion and communication. $^{1824-30}$ 33-37 39-41 43-60 62-70 74-78 8182 86 88-104 Our findings reflect that of previous studies, ${ }^{105}$ which show that family/carers experience distress, guilt, reluctance to call FRs, fear of disproportionate use of force and relief for having FR support. From the FR perspective, the presence of companions during the crisis complicates the response, necessitating attempts to calm the PMI while acknowledging family/carers distress. FRs described both the invaluable presence of companions in terms of giving information, and how their involvement could hinder their response, for example, when the PMI does not trust or wants the companion involved. Future research should explore how FRs navigate these complex relationships and use a compassionate and constructive/beneficial approach when third parties are involved.

\section{Strengths and limitations}

This review used a rigorous methodology, including a comprehensive literature search, clearly defined inclusion criteria and independent screening and data extraction. Of the 79 included studies, 41 were published since 2015 indicating that most research on this topic is contemporary. All of the nine subthemes were consistently reported by at least 12 studies and all included studies used first-order interpretation (direct quotes from participants) strengthening the analysis. However, only studies published in English were included and the focus of the review was limited to interactions and personal experiences and did not include effectiveness studies of interventions to improve MHC response. This study did not explore specific mental health problems. Further research could investigate whether FRs' response to people with different diagnoses varies and how. Differences between countries was not systematically explored. Despite potential significant differences in policing and mental health services in the countries where included studies were conducted, analytic patterns of experiences (themes and subthemes) were found across different countries. However, the majority of these studies were in highincome countries and studies not reported in English were not included. Further research could explore if there is variation in the response, by country with regard to culture, or regulations.

\section{CONCLUSION}

This review demonstrates the variety of experiences and complexity of responding to an MHC and the many diverse challenges FRs face. During MHCs, FRs are responding to the individual in crisis, seeking information and dealing with distressed family/carers, who can either by helpful or obstructive in resolving the crises. Future research is required into how FRs navigate this triadic relationship in the context of an MHC. All stakeholders call for improved training and this review displays instances where training has been effective in eliminating stigma and less use of force. FRs preference of 'on-the-job' training implies the importance of FRs sharing practical knowledge and future research can investigate how to do this in the hectic settings of police and ambulance stations. The belief that FRs are not qualified to respond to MHC is somewhat valid. Training and education in first response to $\mathrm{MCH}$ should consider these issues as well as broader issues of legitimacy and procedural/institutional barriers.

\section{Twitter Jemima Dooley @DrMimaDooley}

Contributors PX conceived the study idea for the qualitative systematic review and is responsible for the overall content (guarantor). CT and PX screened all titles and abstracts and JD acted as a third reviewer. PX and CT wrote the first draft of the paper. JD contributed critically to interpretation of data and revisions of manuscript drafts. All authors approved the final version.

Funding This study was funded by University of Exeter.

Competing interests None declared.

Patient consent for publication Not applicable.

Ethics approval This study does not involve human participants.

Provenance and peer review Not commissioned; externally peer reviewed.

Data availability statement No data are available. No additional data are available. 
Supplemental material This content has been supplied by the author(s). It has not been vetted by BMJ Publishing Group Limited (BMJ) and may not have been peer-reviewed. Any opinions or recommendations discussed are solely those of the author(s) and are not endorsed by BMJ. BMJ disclaims all liability and responsibility arising from any reliance placed on the content. Where the content includes any translated material, BMJ does not warrant the accuracy and reliability of the translations (including but not limited to local regulations, clinical guidelines, terminology, drug names and drug dosages), and is not responsible for any error and/or omissions arising from translation and adaptation or otherwise.

Open access This is an open access article distributed in accordance with the Creative Commons Attribution Non Commercial (CC BY-NC 4.0) license, which permits others to distribute, remix, adapt, build upon this work non-commercially, and license their derivative works on different terms, provided the original work is properly cited, appropriate credit is given, any changes made indicated, and the use is non-commercial. See: http://creativecommons.org/licenses/by-nc/4.0/.

\section{ORCID iDs}

Penny Xanthopoulou http://orcid.org/0000-0002-1510-3382

Jemima Dooley http://orcid.org/0000-0003-3418-8112

\section{REFERENCES}

1 Lavoie JAA. Relative invisibility: an integrative review of carers' lived experiences of a family member's emergency mental health crisis. Soc Work Ment Health 2018;16:601-26.

2 Mind. Mind warns of 'second pandemic' as it reveals more people in mental health crisis than ever recorded and helpline calls soar. Mind, 2020. Available: https://www.mind.org.uk/news-campaigns/ news/mind-warns-of-second-pandemic-as-it-reveals-more-peoplein-mental-health-crisis-than-ever-recorded-and-helpline-calls-soar/ [Accessed 30 Mar 2021].

3 Kane E, Evans E, Shokraneh F. Effectiveness of current policingrelated mental health interventions: a systematic review. Crim Behav Ment Health 2018;28:108-19.

4 Livingston JD. Contact between police and people with mental disorders: a review of rates. Psychiatr Serv 2016;67:850-7.

5 Hallett N, Duxbury J, McKee T, et al. Taser use on individuals experiencing mental distress: an integrative literature review. $J$ Psychiatr Ment Health Nurs 2021;28:56-71.

6 World Health Organization. User empowerment in mental health: a statement by the who regional office for Europe-empowerment is not a destination, but a journey, 2010. Available: www.euro.who. int/ data/assets/pdf file/0020/113834/E93430.pdf

7 Puntis S, Perfect D, Kirubarajan A, et al. A systematic review of co-responder models of police mental health 'street' triage. BMC Psychiatry 2018;18:256.

8 Berry M. College of Paramedics evidence into mental health care and policing. Journal of Paramedic Practice 2014:6:539-40.

9 Rodgers M, Thomas S, Dalton J, et al. Police-related triage interventions for mental health-related incidents: a rapid evidence synthesis. Health Services and Delivery Research 2019;7:1-164.

10 Legislation.gov.uk. Mental Health Act 1983. Section 136. [Internet], 1983. Available: https://www.legislation.gov.uk/ukpga/1983/20/ section/136 [Accessed 30 Mar 2021].

11 Legislation.gov.uk. Policing and Crime Act 2017, Part 4, Chapter 4. [Internet], 2014. Available: https://www.legislation.gov.uk/ukpga/ 2017/3/part/4/chapter/4 [Accessed 30 Mar 2021].

12 Hacker RL, Horan JJ. Policing people with mental illness: experimental evaluation of online training to de-escalate mental health crises. J Exp Criminol 2019;15:551-67.

13 Parker A, Scantlebury A, Booth A, et al. Interagency collaboration models for people with mental ill health in contact with the police: a systematic scoping review. BMJ Open 2018;8:e019312.

14 Morabito MS, Savage J, Sneider L, et al. Police response to people with mental illnesses in a major U.S. City: the Boston experience with the Co-Responder model. Vict Offender 2018;13:1093-105.

15 Zayed MG, Williams V, Glendenning AC, et al. Care-pathways for patients presenting to emergency ambulance services with selfharm: national survey. Emerg Med J 2020;37:752-5.

16 Butler A. A qualitative study of police interactions as perceived by people living with mental disorder [Internet]. Summit.sfu.ca, 2014. Available: https://summit.sfu.ca/item/13903 [Accessed 31 Mar 2021].

17 Callender M, Knight LJ, Moloney D, et al. Mental health street triage: comparing experiences of delivery across three sites. $J$ Psychiatr Ment Health Nurs 2021;28:16-27.
18 Wood JD, Watson AC, Barber C. What can we expect of police in the face of deficient mental health systems? qualitative insights from Chicago police officers. $J$ Psychiatr Ment Health Nurs 2021;28:28-42.

19 Methley AM, Campbell S, Chew-Graham C, et al. PICO, PICOS and spider: a comparison study of specificity and sensitivity in three search tools for qualitative systematic reviews. BMC Health Serv Res 2014;14:579.

20 Critical Appraisal Skills Programme. CASP Checklist: 10 questions to help you make sense of qualitative research. [Internet]., 2018. Available: https://casp-uk.net/wp-content/uploads/2018/01/CASPQualitative-Checklist-2018.pdf [Accessed 30 March 2021].

21 Noyes SNoyes J, Lewin S. Noyes S, Booth A, eds. Supplementary Guidance for Inclusion of Qualitative Research in Cochrane Systematic Reviews of Interventions. Chapter 5: Extracting qualitative evidence. [Internet], 2011. http://cqrmg.cochrane.org/ supplemental-handbook-guidance

22 Baker D, Pillinger C. 'If You call 911 they are going to kill me': families' experiences of mental health and deaths after police contact in the United States. Policing and Society 2020;30:674-87.

23 Baker D, Pillinger C. 'These people are vulnerable, they aren't criminals': Mental health, the use of force and deaths after police contact in England. The Police Journal 2020;93:65-81.

24 Daggenvoorde TH, Gijsman HJ, Goossens PJJ. Emergency care in case of acute psychotic and/or manic symptoms: lived experiences of patients and their families with the first interventions of a mobile crisis team. A phenomenological study. Perspect Psychiatr Care 2018;54:462-8.

25 Herrington V, Pope R. The impact of police training in mental health: an example from Australia. Policing and Society 2014;24:501-22.

26 McGuinness D, Dowling M, Trimble T. Experiences of involuntary admission in an Approved mental health centre. J Psychiatr Ment Health Nurs 2013;20:726-34.

27 Warrington C. Repeated police mental health act Detentions in England and Wales: trauma and recurrent suicidality. Int J Environ Res Public Health 2019;16:4786.

28 Watson AC, Angell B, Morabito MS, et al. Defying negative expectations: dimensions of fair and respectful treatment by police officers as perceived by people with mental illness. Adm Policy Ment Health 2008;35:449-57.

29 Watson AC, Wood JD. Everyday police work during mental health encounters: a study of call resolutions in Chicago and their implications for diversion. Behav Sci Law 2017;35:442-55.

30 Wells W, Schafer JA. Officer perceptions of police responses to persons with a mental illness. Policing 2006;29:578-601.

31 Wood JD, Beierschmitt L. Beyond police crisis intervention: moving "upstream" to manage cases and places of behavioral health vulnerability. Int J Law Psychiatry 2014;37:439-47.

32 Wood JD, Watson AC. Improving police interventions during mental health-related encounters: past, present and future. Policing Soc 2017;27:289-99.

33 Holmes L. "I Just Felt Like I Was in a Cage": Examining the Accounts of Returned Missing Adults With Mental Health Issues. Illness, Crisis \& Loss 2017;25:5-26.

34 Tully T, Smith M. Officer perceptions of crisis intervention team training effectiveness. The Police Journal 2015;88:51-64.

35 Canada KE, Angell B, Watson AC. Intervening at the entry point: differences in how CIT trained and non-CIT trained officers describe responding to mental health-related calls. Community Ment Health J 2012;48:746-55.

36 Morgan M, Paterson C. 'It's Mental Health, Not Mental Police': A Human Rights Approach to Mental Health Triage and Section 136 of the Mental Health Act 1983. Policing-a Journal of Policy and Practice 2019;13:123-33.

37 Soares R, Pinto da Costa M. Experiences and perceptions of police officers concerning their interactions with people with serious mental disorders for compulsory treatment. Front Psychiatry 2019;10:187.

38 Bohrman C, Blank Wilson A, Watson A, et al. How police officers assess for mental illnesses. Vict Offender 2018;13:1077-92.

39 Salerno AC, Schuller RA. A mixed-methods study of police experiences of adults with autism spectrum disorder in Canada. Int J Law Psychiatry 2019;64:18-25.

40 White C, Goldberg V, Hibdon J, et al. Understanding the role of service providers, land use, and resident characteristics on the occurrence of mental health crisis calls to the police. J Community Psychol 2019;47:1961-82.

41 Cheng SC, Backonja U, Buck B, et al. Facilitating pathways to care: a qualitative study of the self-reported needs and coping skills of caregivers of young adults diagnosed with early psychosis. $J$ Psychiatr Ment Health Nurs 2020;27:368-79. 
42 Adio OA, Ikuma LH, Dunn S, et al. Community Paramedics' perception of frequent ED users and the community Paramedicine program: a mixed-methods study. $J$ Health Care Poor Underserved 2020;31:1134-51

43 DeJean D, Giacomini M, Welsford M, et al. Inappropriate Ambulance Use: A Qualitative Study of Paramedics' Views. Hcpol 2016;11:67-79.

44 Ferguson N, Savic M, McCann TV, et al. "I was worried if I don't have a broken leg they might not take it seriously": Experiences of men accessing ambulance services for mental health and/or alcohol and other drug problems. Health Expect 2019;22:565-74.

45 Livingston JD, Desmarais SL, Verdun-Jones S, et al. Perceptions and experiences of people with mental illness regarding their interactions with police. Int $J$ Law Psychiatry 2014;37:334-40.

46 Sondhi A, Luger L, Toleikyte L, et al. Patient perspectives of being detained under section 136 of the mental health act: findings from a qualitative study in London. Med Sci Law 2018;58:159-67.

47 Spence W, Millott J. An exploration of attitudes and support needs of police officer negotiators involved in suicide negotiation. Police Practice and Research 2016;17:5-21.

48 Stokoe E, Sikveland RO. The backstage work negotiators do when communicating with persons in crisis. Journal of Sociolinguistics 2020;24:185-208.

49 Brennan A, Warren N, Peterson V, et al. Collaboration in crisis: carer perspectives on police and mental health professional's responses to mental health crises. Int J Ment Health Nurs 2016;25:452-61.

50 Gibbs V, Haas K. Interactions between the police and the autistic community in Australia: experiences and perspectives of autistic adults and Parents/Carers. J Autism Dev Disord 2020;50:4513-26.

51 McLean N, Marshall LA. A front line police perspective of mental health issues and services. Crim Behav Ment Health 2010;20:62-71.

52 Gregory MJ, Thompson A. From here to Recovery: One Service User's Journey through a Mental Health Crisis: Some Reflections on Experience, Policy and Practice. Journal of Social Work Practice 2013;27:455-70.

53 Schulenberg JL. Police Decision-Making in the Gray Zone:The Dynamics of Police-Citizen Encounters With Mentally III Persons. Criminal Justice and Behavior 2016;43:459-82.

54 Shaban RZ. Paramedic clinical judgement and decision-making of mental illness in the pre-hospital emergency care setting: a case study of accounts of practice. Griffith University, 2011.

55 Wallace WC. Exploring police response and interaction with people with mental illness in Guyana. Policing and Society 2020;30:1226-42

56 McCann TV, Savic M, Ferguson N, et al. Paramedics' perceptions of their scope of practice in caring for patients with non-medical emergency-related mental health and/or alcohol and other drug problems: a qualitative study. PLoS One 2018;13:e0208391.

57 Ross V, Koo YW, Kõlves K. A suicide prevention initiative at a jumping site: a mixed-methods evaluation. EClinicalMedicine 2020;19:100265.

58 Krayer A, Robinson CA, Poole R. Exploration of joint working practices on anti-social behaviour between criminal justice, mental health and social care agencies: a qualitative study. Health Soc Care Community 2018;26:e431-41.

59 McKenna B, Furness T, Oakes J, et al. Police and mental health clinician partnership in response to mental health crisis: a qualitative study. Int J Ment Health Nurs 2015;24:386-93.

60 Oxburgh L, Gabbert F, Milne R, et al. Police officers' perceptions and experiences with mentally disordered suspects. Int J Law Psychiatry 2016;49:138-46.

61 Young L, Digel Vandyk A, Daniel Jacob J, et al. Being parent caregivers for adult children with schizophrenia. Issues Ment Health Nurs 2019;40:297-303.

62 Lane R. "I'm a police officer not a social worker or mental health nurse": Online discourses of exclusion and resistance regarding mental health-related police work. J Community App/ Soc Psychol 2019;29:429-42.

63 Ford-Jones PC. Mental health and psychosocial calls in the prehospital setting in Ontario: A qualitative case study. [Internet], 2020. Available: https://yorkspace.library.yorku.ca/xmlui/handle/ 10315/37469 [Accessed 31 Mar 2021].

64 van Steden R. Governing through care: a qualitative assessment of team play between police and nurses for people with mental illness. Int J Law Psychiatry 2020;68:101532.

65 Davey S, Gordon S, Tester R. Addressing police discrimination regarding mental distress using a service user-led and interpersonal contact/education based 'e-Learning'. Police Practice and Research 2021;22:426-42.

66 Olasoji M, Maude P, McCauley K. Not sick enough: experiences of carers of people with mental illness negotiating care for their relatives with mental health services. $J$ Psychiatr Ment Health Nurs 2017;24:403-11.

67 Dyer W, Steer M, Biddle P. Mental health street triage. Policing 2015:9:377-87.

68 Hanafi S, Bahora M, Demir BN, et al. Incorporating crisis intervention team (CIT) knowledge and skills into the daily work of police officers: a focus group study. Community Ment Health $J$ 2008;44:427-32.

69 Copeland DA, Heilemann MV. Getting "to the point": the experience of mothers getting assistance for their adult children who are violent and mentally ill. Nurs Res 2008;57:136-43.

70 Haas K, Gibbs V. Does a person's autism play a role in their interactions with police: the perceptions of autistic adults and Parent/Carers. J Autism Dev Disord 2021:51:1628-40.

71 Morabito MS. The evolving police response to individuals with behavioral health challenges. Vict Offender 2018;13:1033-6.

72 Morabito MS, Socia K, Wik A, et al. The nature and extent of police use of force in encounters with people with behavioral health disorders. Int J Law Psychiatry 2017;50:31-7.

73 Chidgey K, Procter N, Baker A, et al. Police response to individuals displaying suicidal or self-harming behaviours: an integrative review. Health Soc Care Community 2019;27:e112-24.

74 Green TM. Police as frontline mental health workers. The decision to arrest or refer to mental health agencies. Int J Law Psychiatry 1997;20:469-86.

75 Keefe B, Carolan K, Wint AJ. Behavioral health emergencies encountered by community Paramedics: lessons from the field and opportunities for skills advancement. The Journal of Behavioral Health Services \& Research 2020:1-12.

76 Lamb V, Tarpey E. 'It's not getting them the support they need': Exploratory research of police officers' experiences of community mental health. The Police Journal 2019;92:277-95.

77 Mahmuda S, Wade-Vallance A, Stosic A, et al. Understanding why frequent users of EMS call 9-1-1: a Grounded theory study. Health Promot Pract 2020;21:440-7.

78 Marsden M, Nigam J, Lemetyinen $\mathrm{H}$, et al. Investigating police officers' perceptions of their role in pathways to mental healthcare. Health Soc Care Community 2020;28:913-21.

79 Carr MJ, Steeg S, Webb RT, et al. Effects of the COVID-19 pandemic on primary care-recorded mental illness and self-harm episodes in the UK: a population-based cohort study. Lancet Public Health 2021;6:e124-35.

80 Ingle HE, Mikulewicz M. Mental health and climate change: tackling invisible injustice. Lancet Planet Health 2020;4:e128-30.

81 Erdner A, Piskator R. Police experiences of committing people with mental illness to a hospital. Issues Ment Health Nurs 2013;34:550-5.

82 Myers N, Sood A, Fox KE, et al. Decision making about pathways through care for racially and ethnically diverse young adults with early psychosis. Psychiatr Serv 2019;70:184-90.

83 Rees N, Rapport F, Thomas G, et al. Perceptions of paramedic and emergency care workers of those who self harm: a systematic review of the quantitative literature. $J$ Psychosom Res 2014;77:449-56.

84 Barratt H, Rojas-García A, Clarke K, et al. Epidemiology of mental health attendances at emergency departments: systematic review and meta-analysis. PLoS One 2016;11:e0154449.

85 Thomas S, Watson A. A focus for mental health training for police. Journal of Criminological Research, Policy and Practice 2017;3:93-104.

86 Booty MD, Williams RG, Crifasi CK. Evaluation of a crisis intervention team pilot program: results from Baltimore, MD. Community Ment Health J 2020;56:251-7.

87 Strand J, Boström P, Grip K. Parents' Descriptions of How Their Psychosis Affects Parenting. J Child Fam Stud 2020;29:620-31.

88 Boscarato K, Lee S, Kroschel J, et al. Consumer experience of formal crisis-response services and preferred methods of crisis intervention. Int J Ment Health Nurs 2014;23:287-95.

89 Brink J, Livingston J, Desmarais S. A study of how people with mental illness perceive and interact with the police. Calgary, $\mathrm{AB}$ Mental Health Commission of Canada, 2011.

90 Dougall SC. Response to mental health calls: The frontline perspectives of police officers, communicators and administrators. [Internet]. Theses and Dissertations (Comprehensive, 2014. Available: https://scholars.wlu.ca/cgi/viewcontent.cgi?article= 2739\&context=etd [Accessed 31 Mar 2021].

91 Ford-Jones PC, Daly T. Filling the gap: mental health and psychosocial paramedicine programming in Ontario, Canada. Health Soc Care Community 2020. doi:10.1111/hsc.13189. [Epub ahead of print: 09 Oct 2020]. 
92 Gerson R, Davidson L, Booty A, et al. Families' experience with seeking treatment for recent-onset psychosis. Psychiatr Serv 2009;60:812-6.

93 Girard V, Bonin JP, Tinland A, et al. Mental health outreach and street policing in the downtown of a large French City. Int J Law Psychiatry 2014;37:376-82.

94 Godfredson JW, Thomas SDM, Ogloff JRP, et al. Police perceptions of their encounters with individuals experiencing mental illness: a Victorian survey. Aust N Z J Criminol 2011;44:180-95.

95 Goodall T, Newton E, Larkin M. What are the critical incidents that affect how people cope with being detained under section 136 of the mental health act $(1983,2007)$ ? Int J Psychiatry Clin Pract 2019;23:194-206.

96 Ogloff JR, Thomas SD, Luebbers S, et al. Policing services with mentally ill people: developing greater understanding and best practice. Aust Psychol 2013;48:57-68.

97 Osafo J, Akotia CS, Quarshie EN-B, et al. Police views of suicidal persons and the law Criminalizing attempted suicide in Ghana: a qualitative study with policy implications. Sage Open 2017;7:215824401773180.

98 Prener C, Lincoln AK. Emergency medical services and "psych calls": Examining the work of urban EMS providers. Am J Orthopsychiatry 2015;85:612-9.

99 Railey KS, Bowers-Campbell J, Love AMA, et al. An exploration of law enforcement officers' training needs and interactions with individuals with autism spectrum disorder. J Autism Dev Disord 2020;50:101-17.
100 Rant B, Bregar B. Understanding the attitudes of paramedics towards suicidal patients. Obzornik zdravstvene nege 2014;48:177-94.

101 Rees N, Rapport F, Snooks H, et al. How do emergency ambulance paramedics view the care they provide to people who self harm? ways and means. Int J Law Psychiatry 2017;50:61-7.

102 Rees N, Porter A, Rapport F, et al. Paramedics' perceptions of the care they provide to people who self-harm: a qualitative study using evolved grounded theory methodology. PLoS One 2018;13:e0205813.

103 Roberts L, Henderson J. Paramedic perceptions of their role, education, training and working relationships when attending cases of mental illness. Australasian Journal of Paramedicine $2009 ; 7$.

104 Rolfe U, Pope C, Crouch R. Paramedic performance when managing patients experiencing mental health issues Exploring paramedics' Presentation of Self. Int Emerg Nurs 2020;49:100828.

105 Winters S, Magalhaes L, Kinsella EA. Interprofessional collaboration in mental health crisis response systems: a scoping review. Disabil Rehabil 2015;37:2212-24.

106 Bendelow G, Warrington CA, Jones A-M, et al. Police detentions of 'mentally disordered persons': A multi-method investigation of section 136 use in Sussex. Med Sci Law 2019;59:95-103.

107 Bradbury J, Hutchinson M, Hurley J, et al. Lived experience of involuntary transport under mental health legislation. Int J Ment Health Nurs 2017;26:580-92. 